\title{
Change in Circuit Configuration of Photovoltaic Modules Using Series/Parallel Switching Circuits Composed of Power MOSFETs
}

\author{
Masamichi Tanemo* Non-member, Koki Matsudate* Non-member \\ Shinichi Nomura ${ }^{* a)}$ Member
}

(Manuscript received July 25, 2018, revised Sep. 2, 2019)

\begin{abstract}
This work discusses the feasibility of series/parallel switching circuits with power MOSFETs to minimize the reduction in the output power of photovoltaic power systems due to the partial shading problems by connecting shaded panels and adjacent panels in parallel. The following observations were made on the basis of the experimental results: 1) When at least one of the photovoltaic panels is shaded, $50 \%$ of the reduction ratio of the solar radiation intensity becomes the lower limit of the threshold value for the series/parallel switching control. 2) The effect of the series/parallel switching control can be expected to be higher when more than two of the photovoltaic panels are shaded. However, the sum of the solar radiation intensities applied to the panels in the parallel circuit should be less than $150 \%$ of the maximum intensity of the photovoltaic power system. 3) The shaded panel, which should be connected to the adjacent panel in parallel, can be detected using bypass current measurements rather than direct measurements of the solar radiation intensity. The authors developed a prototype of a switching circuit module and performed the operation tests by using three photovoltaic panels. The results showed that the switching circuit module successfully detects the partial shading conditions and switches from the series operation mode to the parallel operation mode.
\end{abstract}

Keywords: partial shading detection, photovoltaic power system, power MOSFET, series/parallel switching control

\section{Introduction}

Photovoltaic power systems are expected to be one of the feasible options for renewable energy systems. However, the output power of a photovoltaic system is significantly reduced, even when the photovoltaic panels are partially shaded. To extract the output power from the photovoltaic system and to prevent the occurrence of a hot spot in the shaded panel due to the partial shading, the following feasible solutions have been largely discussed so far:

(1) Use of active bypass circuits instead of traditional antiparallel bypass diodes ${ }^{(1)}$.

(2) Power assist by modular DC-DC converters incorporated into photovoltaic modules ${ }^{(2)(3)}$.

(3) Circuit configuration change of photovoltaic panel strings ${ }^{(4)(5)}$.

In this work, the authors focus on the third solution to improve the partial shading problem. Nguyen et al. proposed an adaptive reconfiguration method between photovoltaic arrays using a switching matrix installed between the fixed part of the photovoltaic arrays and the adaptive bank of the solar cells ${ }^{(4)}$. The switching matrix connects each solar cell in the adaptive bank to any row of the solar cells in the fixed part to compensate for the shaded cells in the fixed part of the photovoltaic arrays. On the other hand, as a case study, Igarashi et al. investigated the partial shading problem in the rooftop

a) Correspondence to: Shinichi Nomura. E-mail: nomuras@meiji. ac.jp

* School of Science and Technology, Meiji University

1-1-1, Higashimita, Tama-ku, Kawasaki 214-8571, Japan photovoltaic system at Tokyo station ${ }^{(5)}$. The change in the circuit configuration using the additional cross wiring between the photovoltaic panel strings and the additional blocking diode for the disconnection of the shaded panels to improve the output power, was discussed.

In this work, the authors discuss the feasibility of series/parallel switching circuits using power MOSFETs. In general, although the shaded panel is disconnected by the bypass diode, the series/parallel switching circuits try to extract the output power from the shaded panel by connecting the shaded panel to the adjacent panel in parallel. In the previous work, the authors investigated the effect of the series/parallel switching control by using solar cells ${ }^{(6)}$. However, the threshold values for the series/parallel switching control have not been optimized for an effective improvement in the output power. In this work, the authors evaluate the maximum power point dependence on the solar radiation disturbance between photovoltaic panels and develop a prototype of a switching circuit module to investigate the control methods for the series/parallel switching circuit. This paper describes the threshold value for the series/parallel switching control and a detection method for the partial shading based on the experimental results and the circuit topology.

\section{Series/Parallel Switching Circuit Topology}

2.1 Basic Configuration Figure 1 shows the basic configuration of the series/parallel switching circuit using power MOSFETs. The adjacent photovoltaic panels are connected through a switching circuit. If both panels are uniformly illuminated by the solar radiation, both panels are 


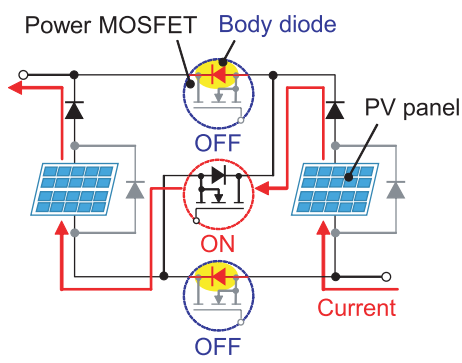

(a) Series operation mode.

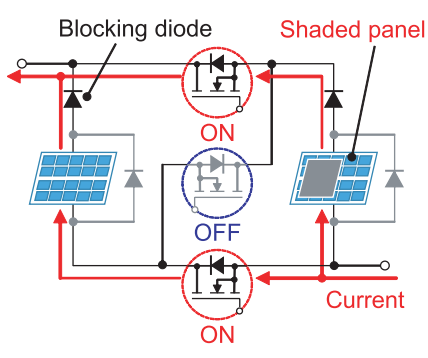

(b) Parallel operation mode.

Fig. 1. Basic configuration of the series/parallel switching circuit for photovoltaic modules. (a) During the normal operation, both panels are connected in series. (b) If one panel is partially shaded, both panels are connected in parallel.

connected in series, as shown in Fig. 1(a). In this normal operation, the center MOSFET is turned on and the other MOSFETs are turned off. As the electrical potential of the panel on the left is higher than that of the panel on the right, the upper branch current can be blocked by the body diode of the MOSFET. The body diode of the MOSFET in the upper branch and that in the lower branch can also be used as a traditional antiparallel bypass diode for the panel on the left and the panel on the right, respectively.

However, if one of the panels is partially shaded, the center MOSFET is turned off, and the other MOSFETs are turned on, as shown in Fig. 1(b). In this case, the shaded panel is connected to the adjacent panel in parallel to extract the output power from the shaded panel. Although the power MOSFETs in the upper and lower branches of the switching circuit can be replaced by diodes in the parallel operation mode, the authors attempted to use the power MOSFETs to reduce the on-state power losses in the switching circuit. The external blocking diodes are composed of Schottky barrier diodes.

2.2 Series/Parallel Switching Circuit Module Prototype Using Power MOSFETs The authors develop a prototype of a switching circuit module for five photovoltaic panels to investigate the control methods of the series/parallel switching circuit for the photovoltaic system. Figure 2(a) shows a photograph of the switching circuit module prototype. As shown in Fig. 2(b), the number of connected photovoltaic panels is determined by the mechanical selector switches (SW1-SW5). For instance, when only switch SW3 is turned on, three photovoltaic panels are connected through the series/parallel switching circuits.

The electric power load for the photovoltaic panels is controlled by the PWM control of the DC/DC boost converter. As shown in Fig. 2(c), the applied PWM signal, with a duty ratio of the power MOSFETs of the boost chopper circuit, is calculated from the microcomputer. By controlling the duty

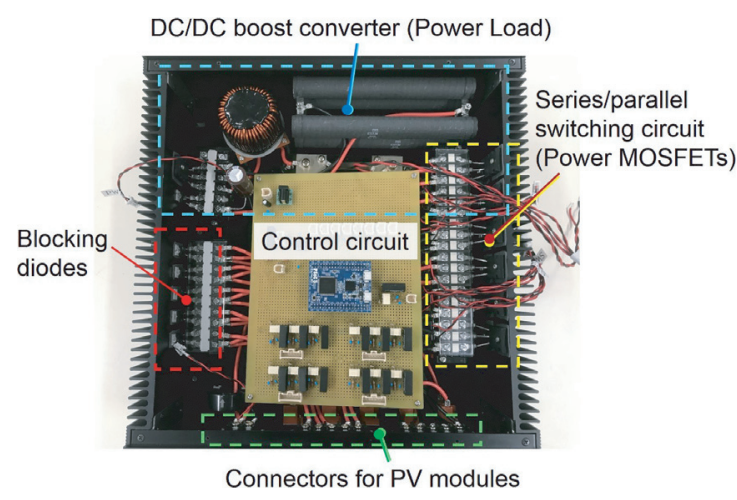

(a) Prototype series/parallel switching circuit module.

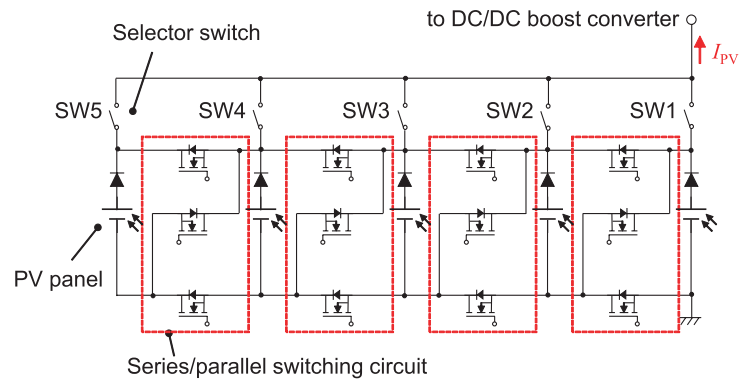

(b) Series/parallel switching circuit.

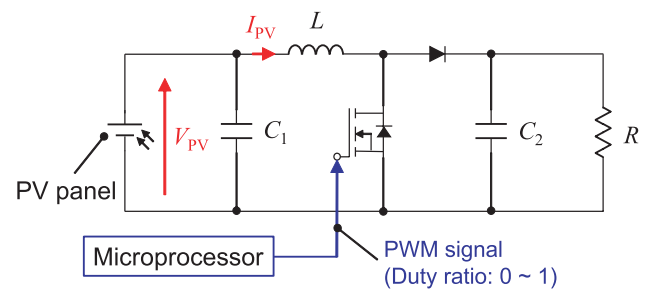

(c) DC/DC boost converter circuit.

Fig. 2. (a) A photograph of the prototype series/parallel switching circuit module for five photovoltaic panels. (b) The number of the operating photovoltaic panels is selected by the selector switches. (c) When SW3 is turned on, three panels are connected to the DC/DC boost converter through the series/parallel switching circuit.

ratio, the output voltage of the solar cell module is changed from $0 \mathrm{~V}$ to the open circuit voltage and the output current is varied from $0 \mathrm{~A}$ to the short circuit current.

The gate signals applied to the power MOSFET of the series/parallel switching circuit are directly provided from the microcomputer. The gate drive circuit for each power MOSFET is insulated by using an isolated DC/DC converter and a photocoupler.

\section{Feasibility of the Series/Parallel Switching Control for Photovoltaic Modules}

3.1 Experimental Conditions The authors investigate the maximum power point dependence on the solar radiation disturbance between photovoltaic panels and evaluate the threshold value for the series/parallel switching control. A photograph and the specifications of the sample photovoltaic panel are shown in Fig. 3 and Table 1, respectively.

Figure 4 shows the relationship between the solar radiation intensity and the output properties at the point where the sample photovoltaic panel has the maximum power. From the results, it can be seen that the maximum power point and 


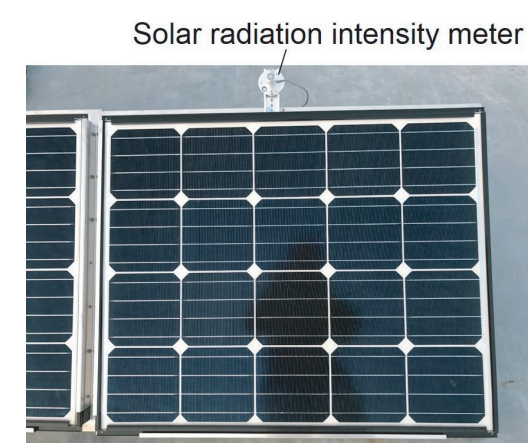

Fig. 3. Sample photovoltaic panel.

Table 1. Specifications of the sample panel.

\begin{tabular}{lr}
\hline Maximum output & $89 \mathrm{~W}$ \\
Open circuit voltage & $12.7 \mathrm{~V}$ \\
Short circuit current & $9.21 \mathrm{~A}$ \\
Maximum operating output voltage & $10.3 \mathrm{~V}$ \\
Maximum operating output current & $8.68 \mathrm{~A}$ \\
\hline
\end{tabular}

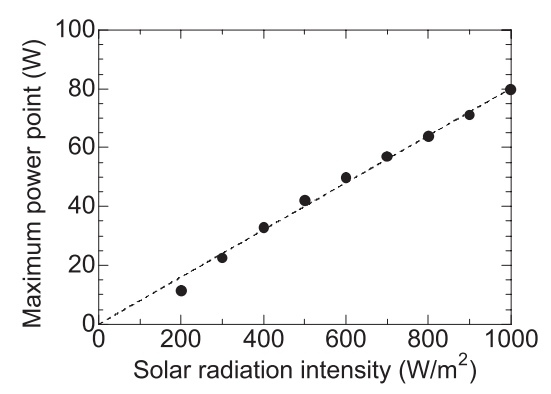

(a) Maximum power point.

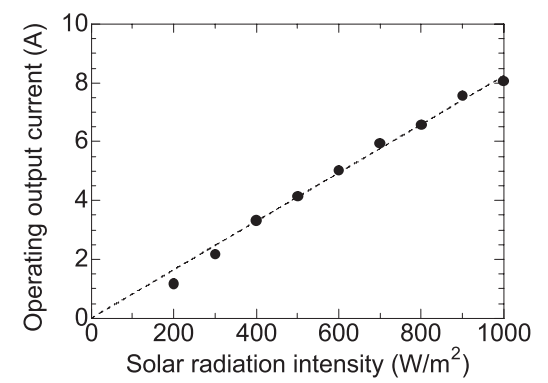

(b) Operating output current at the maximum power point.

Fig. 4. (a) The maximum power point and (b) the operating current output of the sample photovoltaic panel as a function of solar radiation intensity. The surface temperature of the photovoltaic panel is $40^{\circ} \mathrm{C}$. The operating output voltage at the maximum power point is approximately $10 \mathrm{~V}$.

the operating output current are proportional to the solar radiation intensity. Compared to the specifications in Table 1, the operating output voltage at the maximum power point is approximately $10 \mathrm{~V}$. Therefore, the threshold value of the series/parallel switching control can be evaluated using the solar radiation disturbance between the photovoltaic panels.

The reduction ratio of the solar radiation intensity, $a_{\text {ratio }}$, between the photovoltaic panels is defined as

$$
a_{\text {ratio }}=\frac{X_{\max }-X_{\min }}{X_{\max }} \times 100 \%, \ldots \ldots \ldots \ldots \ldots \ldots
$$

where $X_{\max }$ is the maximum solar radiation intensity applied to the panel, and $X_{\min }$ is the minimum solar radiation intensity of the shaded panels. If $a_{\text {ratio }}$ is $0 \%$, it implies that all
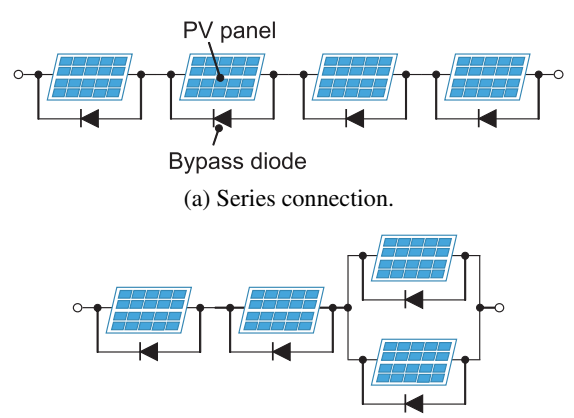

(b) Parallel connection with two panels.

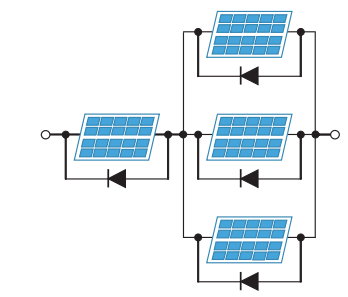

(c) Parallel connection with three panels.

Fig. 5. The circuit configuration change patterns are (a) all photovoltaic panels connected in series, (b) two panels connected in parallel, and (c) three panels connected in parallel.

the photovoltaic panels are uniformly illuminated. If $a_{\text {ratio }}$ is $100 \%$, it implies that the photovoltaic panel is completely shaded $\left(0 \mathrm{~W} / \mathrm{m}^{2}\right)$.

Four photovoltaic panels are used for the investigation of the threshold value for the series/parallel switching control. The circuit configuration change patterns of the four panels are summarized in Fig. 5. In this experiment, mechanical switches are used for the series/parallel switching instead of the power MOSFETs.

\subsection{Case Studies of One Shaded Photovoltaic Panel}

Figure 6 compares the maximum power points of the parallel connections of the photovoltaic panels to those in the series connection when only one of the panels is shaded and the other panels are uniformly illuminated by the solar radiation. Figure 6(a) shows the circuit configuration change patterns of the shaded panel. The maximum solar radiation, $X_{\max }$, is $1000 \mathrm{~W} / \mathrm{m}^{2}$. The solar radiation of the shaded panel, $X_{\min }$, varies from $200-1000 \mathrm{~W} / \mathrm{m}^{2}$.

From the results in Fig. 6(b), it can be observed that when the reduction ratio of the solar radiation intensity, $a_{\text {ratio }}$, is over $50 \%$, the maximum power point in the series connection becomes a constant value. This property shows that the shaded panel is disconnected by the bypass diode. Consequently, the maximum power point shifts to the lower voltage side.

On the other hand, the maximum power point in the parallel connections is approximately the same as the maximum power which is obtained when the three photovoltaic panels are illuminated uniformly, even when the solar radiation of the shaded panel is reduced. However, from the results in Fig. 6(c), it can be seen that when the reduction ratio of the solar radiation intensity, $a_{\text {ratio }}$, is more than $50 \%$, the maximum power in the case of two panels connected in parallel is $10-20 \%$ higher than that in the case of the series connection by the effect of the reduction in the internal resistance. 


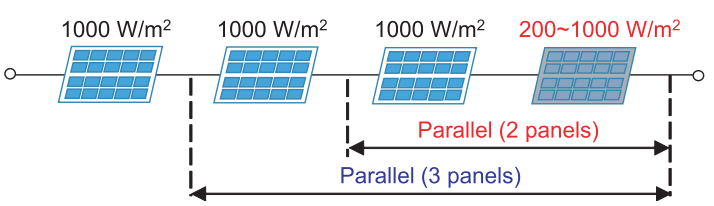

(a) Experimental conditions.

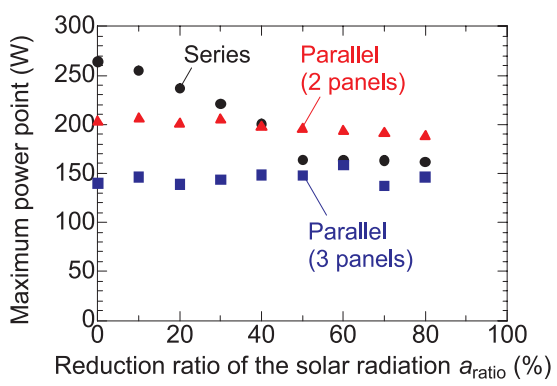

(b) Maximum power point.

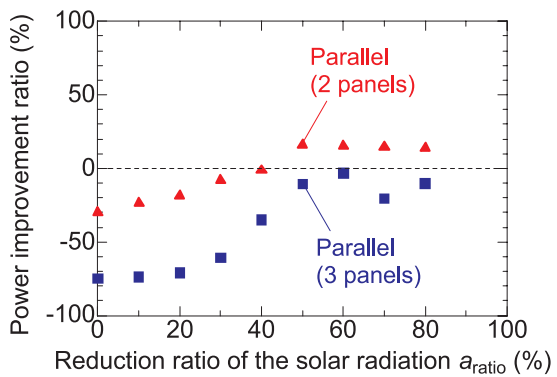

(c) Power improvement ratio.

Fig. 6. (a) The maximum power point dependence on the solar radiation disturbance when one of the photovoltaic panels is shaded. The detailed circuit configurations are shown in Fig. 5. (b) The maximum power points are compared between the series connection and the parallel connections of the photovoltaic panels. (c) The ratio of the power improvement to the series connection case is compared between the case of two panels connected in parallel and the case of three panels connected in parallel under the same condition of the solar radiation disturbance.

\subsection{Case Studies of Two Shaded Photovoltaic Panels}

In Fig. 7, the maximum power points of the photovoltaic panels in parallel is compared to those in series, when two of the panels are shaded. Figure 7(a) shows the change patterns of the circuit configurations of the shaded panels. Two of the photovoltaic panels are constantly illuminated by a solar radiation of $1000 \mathrm{~W} / \mathrm{m}^{2}$, whose value corresponds to the maximum intensity, $X_{\max }$. The other panels are shaded with a solar radiation ranging from $200-1000 \mathrm{~W} / \mathrm{m}^{2}$, whose values correspond to $X_{\min }$. All combinations of the solar radiation disturbances were evaluated.

From the results in Fig. 7(b) and Fig. 7(c), it can be observed that if the reduction ratio of the solar radiation intensity, $a_{\text {ratio }}$, is over $50 \%$, the parallel connections can maintain a higher output power from the photovoltaic power system compared to the series connection under the same condition of the solar radiation disturbance. Comparing the results in Fig. 7(c) to those in Fig. 6(c), it can be observed that power improvement using the series/parallel switching control can be expected to be higher when more than two of the photovoltaic panels are simultaneously shaded. Therefore, a 50\% reduction ratio of the solar radiation intensity becomes one of

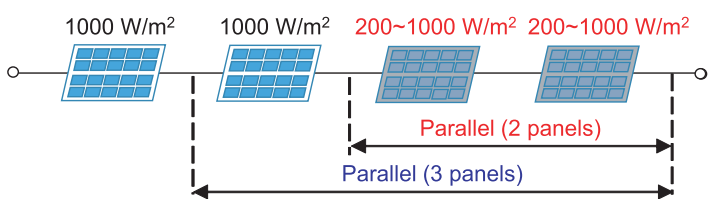

(a) Experimental conditions.

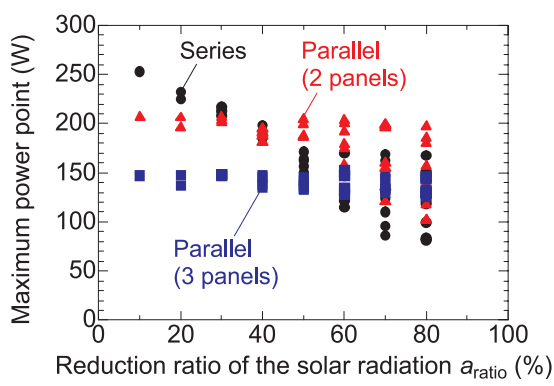

(b) Maximum power point.

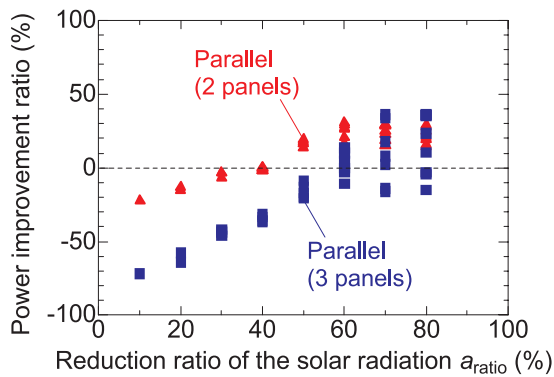

(c) Power improvement ratio.

Fig. 7. (a) The maximum power point dependence on the solar radiation disturbance when two of the photovoltaic panels are shaded. The detailed circuit configurations are shown in Fig. 5. (b) The maximum power points are compared between the series connection and the parallel connections of the photovoltaic panels. (c) The ratio of the power improvement to the series connection case is compared between the case of two panels connected in parallel and the case of three panels connected in parallel under the same condition of the solar radiation disturbance.

the threshold values for the series/parallel switching control. However, there are some cases, especially the one when three panels are connected in parallel, which cannot improve the maximum power point. The validity of the threshold value is discussed in Section 4.

3.4 Case Studies of Three Shaded Photovoltaic Panels

In Fig. 8, the maximum power points of the photovoltaic panels in parallel is compared to those in series, when three of the panels are shaded. Figure 8(a) shows the change patterns of the circuit configurations of the shaded panels. One of the photovoltaic panels is constantly illuminated by a solar radiation of $1000 \mathrm{~W} / \mathrm{m}^{2}$, whose value corresponds to the maximum intensity, $X_{\max }$. The other panels are shaded with a solar radiation ranging from $200-1000 \mathrm{~W} / \mathrm{m}^{2}$, whose values correspond to $X_{\min }$. However, the typical combinations of the solar radiation disturbances were investigated.

From the results in Fig. 8(b) and Fig. 8(c), it can be observed that when the reduction ratio of the solar radiation intensity, $a_{\text {ratio }}$, is over $50 \%$, when the two panels are connected in parallel, and the output power can be extracted from the shaded panels under the same condition as that of the solar radiation disturbance. Compared to the case of the series 


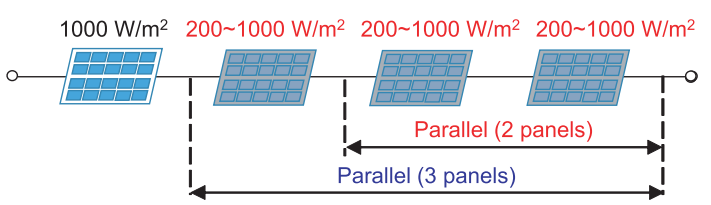

(a) Experimental conditions.

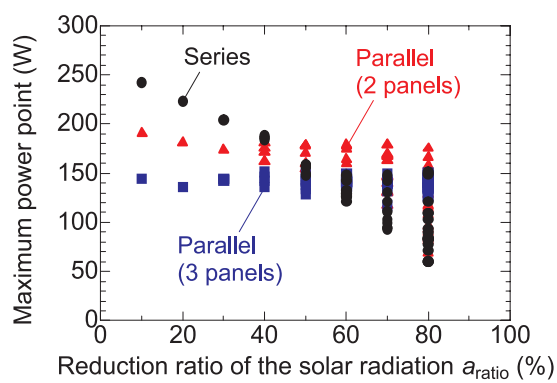

(b) Maximum power point.

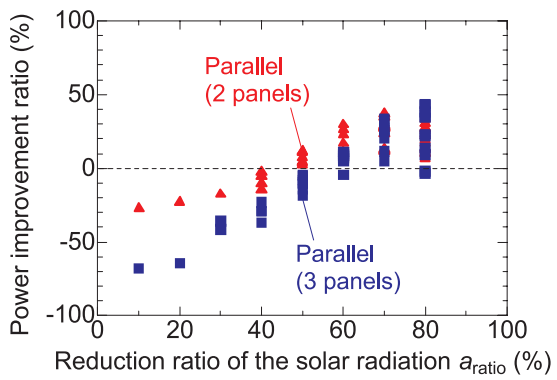

(c) Power improvement ratio.

Fig. 8. (a) The maximum power point dependence on the solar radiation disturbance when three of the photovoltaic panels are shaded. The detailed circuit configurations are shown in Fig. 5. (b) The maximum power points are compared between the series connection and the parallel connections of the photovoltaic panels. (c) The ratio of the power improvement to the series connection case is compared between the case of two panels connected in parallel and the case of three panels connected in parallel under the same condition of the solar radiation disturbance.

connection, the maximum ratio of the power improvement becomes $30 \%$. In the case of three panels connected in parallel, if the reduction ratio of the solar radiation intensity, $a_{\text {ratio }}$, is over $60 \%$, there are some cases which can be expected to improve the maximum power point properties by the effect of the series/parallel switching control.

\section{Evaluation of the Threshold Values for the Se- ries/Parallel Switching Control}

4.1 Lower Limit of the Threshold Value From the results in the previous section, it can be seen that $50 \%$ of the reduction ratio of the solar radiation intensity, $a_{\text {ratio }}$, becomes one of the threshold values for the series/parallel switching control. To evaluate the validity of this threshold value, the authors carried out certain case studies using the switching circuit module prototype shown in Fig. 2.

Figure 9 shows an example of the output properties for three photovoltaic panels with $50 \%$ of the reduction ratio of the solar radiation intensity $\left(a_{\text {ratio }}=50 \%\right)$. One of the panels is shaded and the other panels are uniformly illuminated by the solar radiation. From Fig. 9(a), it can be seen that in the series connection, the maximum power point shifts to the lower voltage side. This property means that the shaded panel

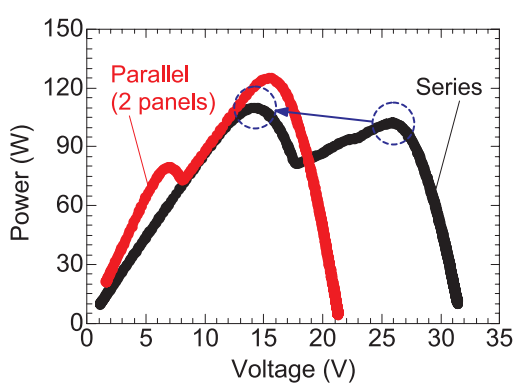

(a) $P$ - $V$ curves.

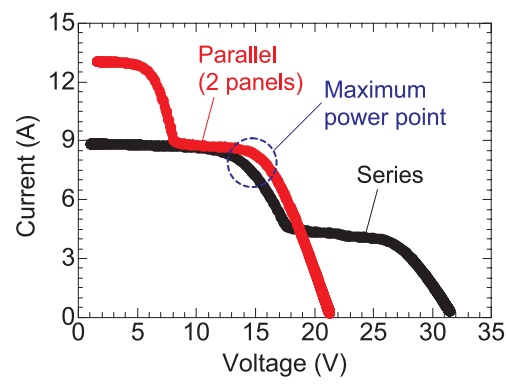

(b) $I-V$ curves.

Fig. 9. Comparison of the (a) $P-V$ curves and the (b) $I-V$ curves between the series connection and the parallel connection with $50 \%$ of the reduction ratio of the solar radiation intensity using three photovoltaic panels. The combination of the solar radiation disturbance is $1000 \mathrm{~W} / \mathrm{m}^{2}-1000 \mathrm{~W} / \mathrm{m}^{2}-500 \mathrm{~W} / \mathrm{m}^{2}$. In the parallel connection, the shaded panel is connected to the adjacent panel in parallel.

is disconnected by the bypass diode. When the shaded panel is connected to the adjacent panel in parallel, the maximum power point is increased by the effect of the reduction of the internal resistance. Therefore, $50 \%$ of the reduction ratio of the solar radiation intensity becomes the lower limit of the threshold value for the series/parallel switching control.

4.2 Limitation of Parallel Connections From the results in Section 3, it can be discerned that even when the reduction ratio, $a_{\text {ratio }}$, is over $50 \%$, there are some cases which cannot obtain the power improvement effect by the parallel connection. In this section, the authors discuss the limitation of the parallel conditions.

Figure 10 shows the output properties with a combination of a solar radiation disturbance of $1000 \mathrm{~W} / \mathrm{m}^{2}-500 \mathrm{~W} / \mathrm{m}^{2}-$ $300 \mathrm{~W} / \mathrm{m}^{2}$. Here, the reduction ratio of the solar radiation intensity, $a_{\text {ratio }}$, becomes $70 \%$. From the results in Fig. 10(a), it can be seen that as the maximum power point in the series connection case shifts to the lower voltage side, the shaded panel illuminated with $300 \mathrm{~W} / \mathrm{m}^{2}$ is disconnected by the bypass diode during the maximum power point tracking (MPPT) operation. In this case, the output current becomes 4.16 A, as shown in Fig. 10(b). If the photovoltaic power system is operated at $28 \mathrm{~V}$, the output voltage is provided from three panels connected in series. However, the output current is limited to $2.02 \mathrm{~A}$ due to the $300-\mathrm{W} / \mathrm{m}^{2}$ shaded panel. Therefore, the output current in the series connection is limited by the shaded panel that is illuminated with the lowest solar radiation intensity.

On the other hand, compared to the series connection, if the shaded panels are connected in parallel, the output voltage at the maximum power point is approximately the same 


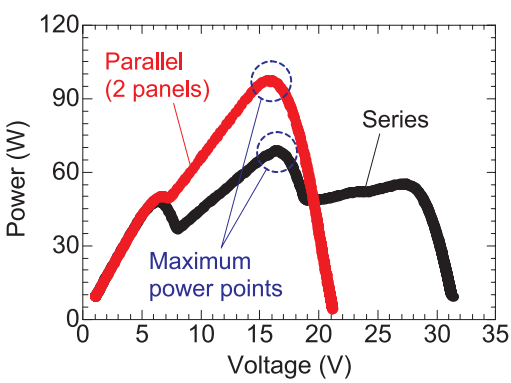

(a) $P$ - $V$ curves.

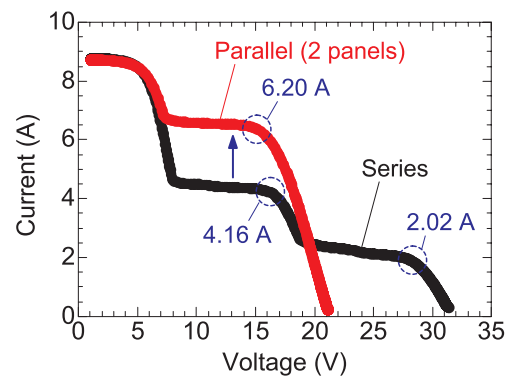

(b) $I$ - $V$ curves.

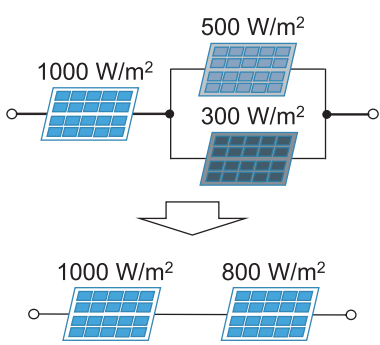

(c) Equivalent disturbance.

Fig. 10. Comparison of the (a) $P-V$ curves and the (b) $I-V$ curves between the series connection and the parallel connection using three photovoltaic panels. The combination of the solar radiation disturbance is $1000 \mathrm{~W} / \mathrm{m}^{2}-$ $500 \mathrm{~W} / \mathrm{m}^{2}-300 \mathrm{~W} / \mathrm{m}^{2}$. (c) After the shaded panels are connected in parallel, the photovoltaic power system can be equivalently evaluated as a series connected panel system with a combination of a solar radiation disturbance of $1000 \mathrm{~W} / \mathrm{m}^{2}-800 \mathrm{~W} / \mathrm{m}^{2}$

as that in the case of the series connection, and the output current is increased to $6.20 \mathrm{~A}$, as shown in Fig. 10(b). The difference in the output current at the maximum power point between the series and the parallel connections is approximately the same as the output current from the shaded panel, i.e., 2.02 A. Therefore, the photovoltaic power system can extract output power from the $300-\mathrm{W} / \mathrm{m}^{2}$ shaded panel via the parallel connection.

From the previous discussion in Section 3.1, as the maximum power point and the operating output current are proportional to the solar radiation intensity under the same operating output voltage, the sum of the output current in the parallel circuit composed of the $500-\mathrm{W} / \mathrm{m}^{2}$ panel and the $300-$ $\mathrm{W} / \mathrm{m}^{2}$ panel is the almost the same as the current from a single panel illuminated with $800 \mathrm{~W} / \mathrm{m}^{2}$ of solar radiation intensity. This means that the shaded panels in the parallel circuit generate almost the same maximum power from a single panel illuminated with $800 \mathrm{~W} / \mathrm{m}^{2}$ of the solar radiation intensity. Therefore, the photovoltaic power system can be equivalently evaluated as a series connected panel system with a combination of a solar radiation disturbance of $1000 \mathrm{~W} / \mathrm{m}^{2}-$

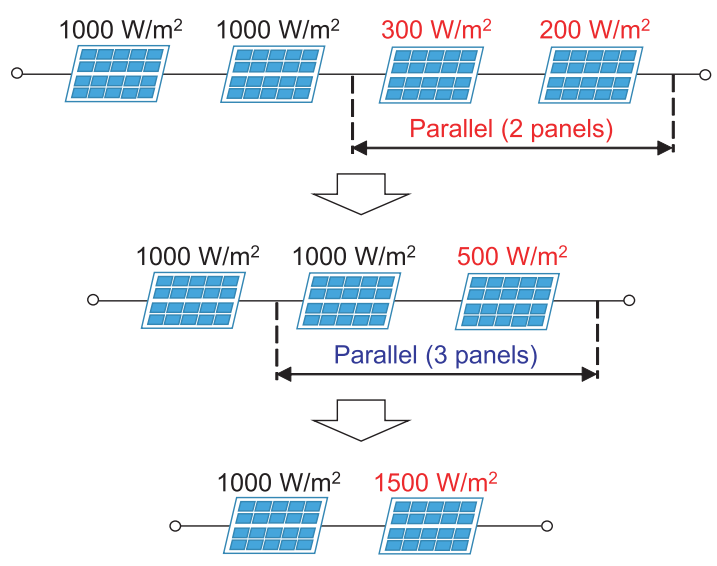

Fig. 11. Example of the series/parallel switching control and its equivalent condition.

$800 \mathrm{~W} / \mathrm{m}^{2}$, as shown in Fig. 10(c). In this case, as the reduction ratio of the solar radiation intensity, $a_{\text {ratio }}$, can be reduced to $20 \%$, the series/parallel switching control leads to power improvement against the partial shading problem.

Figure 11 shows an example of the series/parallel switching condition. In this example, the reduction ratio of the solar radiation intensity, $a_{\text {ratio }}$, is $80 \%$. When the $200-\mathrm{W} / \mathrm{m}^{2}$ shaded panel is connected to the $300-\mathrm{W} / \mathrm{m}^{2}$ panel in parallel, the combination of the solar radiation disturbance is reduced equivalently to $1000 \mathrm{~W} / \mathrm{m}^{2}-1000 \mathrm{~W} / \mathrm{m}^{2}-500 \mathrm{~W} / \mathrm{m}^{2}$ and the reduction ratio of the solar radiation intensity, $a_{\text {ratio }}$, becomes $50 \%$, which is the lower limit of the threshold value for the series/parallel switching control discussed in Fig. 9. As shown in Fig. 11, three panels can be connected in parallel to obtain the effect of the series/parallel switching control. Therefore, the sum of the solar radiation intensity applied to the photovoltaic panels in the parallel circuit should be less than $150 \%$ of the maximum intensity of the photovoltaic power system.

\section{Control Methods of the Series/Parallel Switch- ing Circuit Module}

5.1 Detection Method of Partial Shading Conditions

As shown in Section 2.1, if partial shading occurs during the series operation mode, the shaded panel is disconnected by the body diode of the power MOSFET in the upper branch or in the lower branch of the series/parallel switching circuit. From this feature, the shaded panel which should be connected to the adjacent panel in parallel can be detected by the bypass current instead of the direct measurement of the solar radiation intensity.

Using the series/parallel switching circuit module prototype shown in Fig. 2, the short circuit test for the three photovoltaic panels connected in series was performed by setting the duty ratio of the DC/DC boost converter to 1 . The solar radiation intensity applied to one shaded panel varied from $100-1000 \mathrm{~W} / \mathrm{m}^{2}$, and the other panels were illuminated by a solar radiation intensity of $1000 \mathrm{~W} / \mathrm{m}^{2}$.

Figure 12 shows the bypass current conditions for both ends of the series/parallel switching circuit module. When the photovoltaic panel on the left end is shaded, the bypass current flows in the upper branch of the switching circuit, as shown in Fig. 12(a). On the other hand, if the photovoltaic 


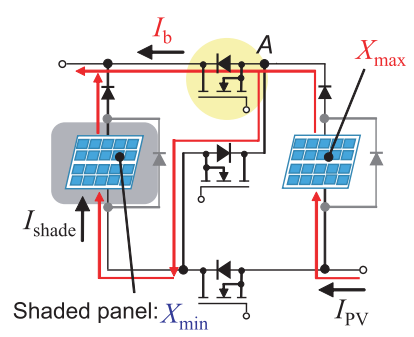

(a) Left end case.

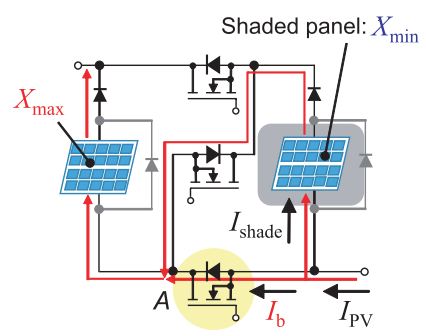

(b) Right end case.

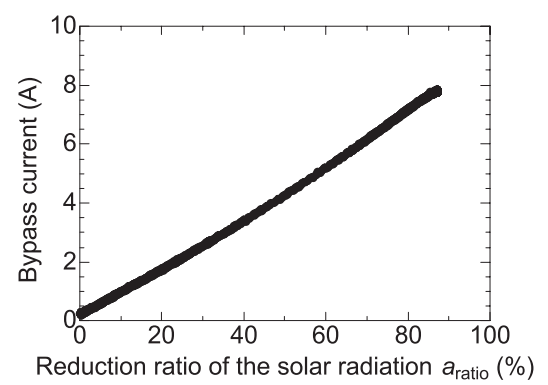

(c) Bypass current condition.

Fig. 12. Bypass current conditions in the (a) left end case and the (b) right end case of the switching circuit module. (c) The bypass current through the upper branch or the lower branch of the switching circuit module is proportional to the reduction ratio of the solar radiation intensity, $a_{\text {ratio }}$.

panel on the right end is shaded, the bypass current flows in the lower branch of the switching circuit, as shown in Fig. 12(b).

Figure 12(c) shows the test result under the condition shown in Fig. 12(b). From the result, it can be seen that the bypass current, $I_{\mathrm{b}}$, is proportional to the reduction ratio of the solar radiation intensity, $a_{\text {ratio }}$. As the output current through the photovoltaic panel is almost proportional to the solar radiation intensity, the relationship between the current through the shaded panel, $I_{\text {shade }}$, and the total current in the photovoltaic power system, $I_{\mathrm{PV}}$, is given by

$$
I_{\text {shade }}=\frac{X_{\min }}{X_{\max }} I_{\mathrm{PV}}
$$

where $X_{\min }$ is the solar radiation intensity applied to the shaded panel, and $X_{\max }$ is the maximum solar radiation intensity. Based on Fig. 12(a) and Fig. 12(b), Kirchhoff's first law at node $A$ becomes

$$
I_{\mathrm{PV}}-I_{\text {shade }}-I_{\mathrm{b}}=0 .
$$

Therefore, using the reduction ratio of the solar radiation intensity, $a_{\text {ratio }}$, defined as (1), the bypass current is approximately given by

$$
I_{\mathrm{b}}=\frac{a_{\mathrm{ratio}}}{100} I_{\mathrm{PV}}
$$

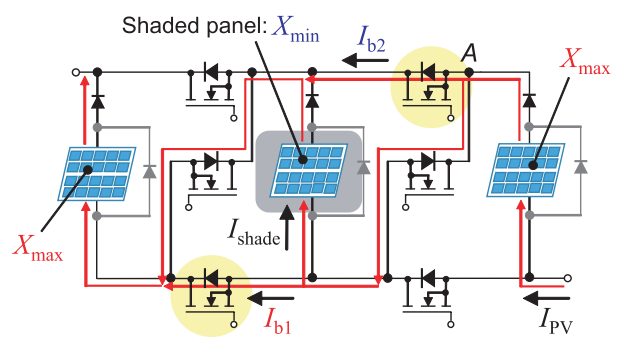

(a) Bypass current path.

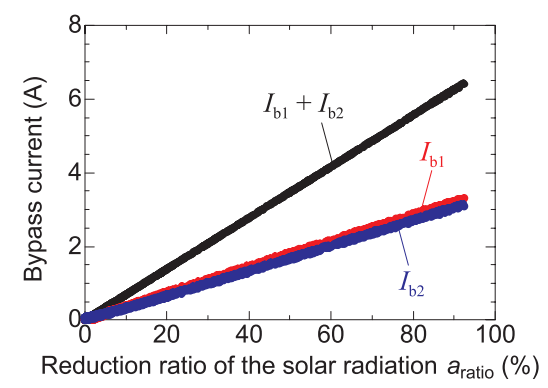

(b) Bypass current condition.

Fig. 13. (a) Bypass current conditions when the photovoltaic panel between the series/parallel switching circuits is shaded. (b) The total bypass current is proportional to the reduction ratio of the solar radiation intensity, $a_{\text {ratio }}$.

This equation indicates that the partial shading condition can be detected by measuring the bypass current. From the results presented in Section 4, it can be seen that $50 \%$ of the reduction ratio of the solar radiation intensity becomes the lower limit of the threshold value for the series/parallel switching control. Therefore, when the bypass current is over $50 \%$ of the total current, the operation mode should be changed from the series operation mode to the parallel operation mode to extract output power from the shaded panel.

On the other hand, when the photovoltaic panel between the series/parallel switching circuits is shaded, the bypass currents flow in both the upper and lower branches of the switching circuits, as shown in Fig. 13(a). From the short circuit test, with a range from $0 \%$ to $90 \%$ of the reduction ratio of the solar radiation intensity, $a_{\text {ratio }}$, the sum of the bypass currents, $I_{\mathrm{b} 1}+I_{\mathrm{b} 2}$, is also proportional to the reduction ratio of the solar radiation intensity, $a_{\text {ratio }}$, as shown in Fig. 13(b). From Fig. 13(a), Kirchhoff's first law at node $A$ becomes

$$
I_{\mathrm{PV}}-I_{\text {shade }}-I_{\mathrm{b} 1}-I_{\mathrm{b} 2}=0 .
$$

From (1), (2), and (5), the sum of the bypass currents is approximately evaluated using

$$
I_{\mathrm{b} 1}+I_{\mathrm{b} 2}=\frac{a_{\text {ratio }}}{100} I_{\mathrm{PV}}
$$

This equation means that the partial shading conditions are detected by measuring the bypass current conditions. Therefore, when the sum of the bypass currents is over $50 \%$ of the total current, the operation mode should be changed from the series operation mode to the parallel operation mode to extract the output power from the shaded panel.

5.2 Demonstration of the Series/Parallel Switching The authors performed the operation test of the partial shading detection and the series/parallel switching operation by using the prototype switching circuit module shown in Fig. 2 . 


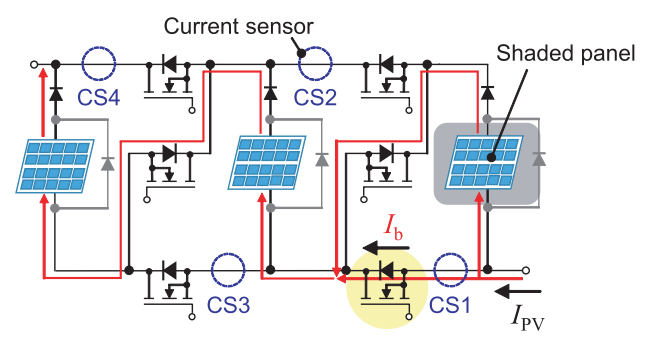

(a) Experimental circuit.

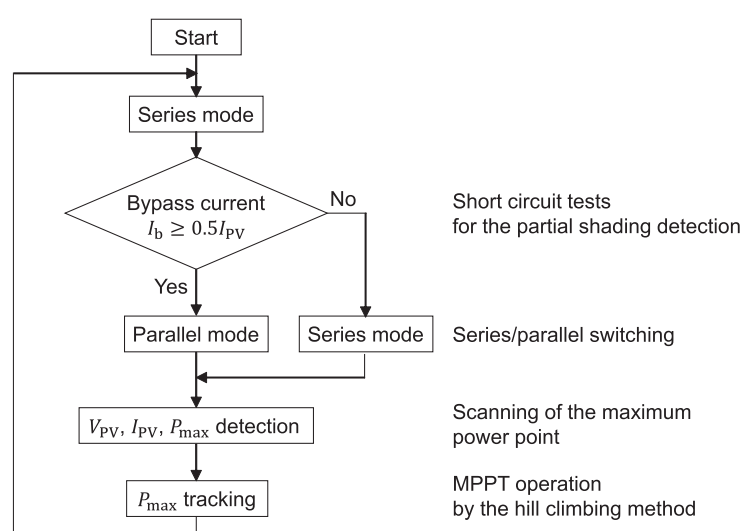

(b) Control procedure.

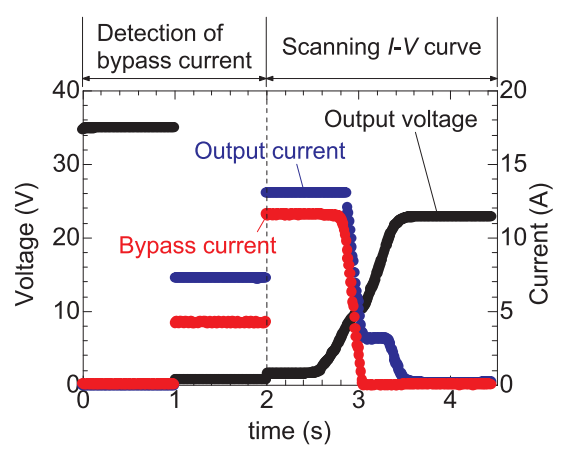

(c) Test results.

Fig. 14. (a) Experimental circuit, (b) the control procedure, and (c) the test results of the series/parallel switching circuit module prototype. $V_{\mathrm{PV}}$ and $I_{\mathrm{PV}}$ are the terminal voltage and the total current of the photovoltaic module, respectively. $P_{\max }$ is the maximum power point.

Figure 14(a) shows the experimental circuit. The right end of the photovoltaic panel (PV3) reduced the applied solar radiation intensity. This condition corresponds to Fig. 12(b). The reduction ratio of the solar radiation intensity, $a_{\text {ratio }}$, is set to $55 \%$. The bypass currents in the upper and lower branches are measured using the current sensors (CS1-CS4).

Figure 14(b) shows the control procedure of the switching circuit module prototype. The control procedure for the MPPT operation is composed of three steps. The first step is the short circuit test, which detects the partial shading conditions by measuring the bypass currents. In the short circuit test, the duty ratio of the PWM signals for the DC/DC boost converter is set to 1 . The DC/DC boost converter circuit controls the output voltage and the output current. According to (4), if the bypass current, $I_{\mathrm{b}}$, is more than $50 \%$ of the output current, $I_{\mathrm{PV}}$, the shaded panel (PV3) is connected to the adjacent panel (PV2) in parallel. The second step is the scanning of the maximum power point by varying the duty ratio of the PWM signals from $0-1$. The third step is the MPPT control using the hill climbing method. In this demonstration, the authors confirm the first and the second steps of the control procedure.

Figure 14(c) shows the test results of the partial shading detection and the series/parallel switching operation. Between $0-1 \mathrm{~s}$, the circuit condition is the open circuit for setting the offsets of the current sensors. In this period, the output voltage is $35 \mathrm{~V}$. This voltage shows that three photovoltaic panels are connected in series. Between 1-2 s, the short circuit test is carried out. In this period, the bypass current is over 50\% of the output current. Then the switching circuit is changed from the series operation mode to the parallel operation mode at $2 \mathrm{~s}$. Between 2-4.5 s, the scanning of the maximum power point is carried out. After the scanning of the maximum power point, the output voltage becomes $23 \mathrm{~V}$. This voltage shows that the shaded panel is connected to the adjacent panel in parallel.

\section{Conclusions}

To minimize the output power reduction of the photovoltaic system due to problems caused by partial shading, the feasibility of series/parallel switching circuits has been discussed. This system attempts to extract output power from the shaded panel by connecting the shaded panel to the adjacent panel in parallel. From the experimental results, we can conclude the following:

(1) When at least one of the photovoltaic panels is shaded, $50 \%$ of the reduction ratio of the solar radiation intensity becomes the lower limit of the threshold values for the series/parallel switching control.

(2) The effect of the series/parallel switching control can be expected to be higher when more than two of the photovoltaic panels are shaded. However, the sum of the solar radiation intensities applied to the photovoltaic panels in the parallel circuit should be less than $150 \%$ of the maximum intensity of the photovoltaic power system.

(3) The shaded panel, which should be parallelly connected to the adjacent panel, can be detected by measuring the bypass current rather than direct measurements of the solar radiation intensity.

The authors developed a prototype of a switching circuit module using power MOSFETs and performed operation tests by using three photovoltaic panels. From the test results, it was concluded that the switching circuit module prototype successfully detected the partial shading conditions by measuring the bypass current and switched from the series operation mode to the parallel operation mode.

In this work, the authors present the threshold values for an effective series/parallel switching control, based on the experimental results obtained using four photovoltaic panels. However, if a complex solar radiation disturbance occurs in the photovoltaic power system, which is composed of more than five panels, the control process of the series/parallel switching may also become complex. For further research on this work, the validity of the series/parallel switching control in a large-scale photovoltaic power system should be investigated. In this case, the number of photovoltaic panels connected in parallel should be optimized considering the required input DC voltage of the power conditioning system 
for the grid connection. In addition to this, the improvement in the power caused by the series/parallel switching control during the MPPT operation should also be compared to that in conventional photovoltaic power systems.

\section{References}

( 1 ) V. d'Alessandro, P. Guerriero, and S. Daliento: "A simple bipolar transistorbased bypass approach for photovoltaic modules", IEEE Journal of Photovoltaic, Vol.4, No.1, pp.405-413 (2014)

( 2 ) G.R. Walker and P.C. Serina: "Cascaded DC-DC converter connection of photovoltaic modules", IEEE Trans. on Power Electronics, Vol.19, No.4, pp.1130-1139 (2004)

( 3 ) E. Roman, R. Alonso, P. Ibanez, S. Elorduizapatarietxe, and D. Goitia: "Intelligent PV module for grid-connected PV systems", IEEE Trans. on Industrial Electronics, Vol.53, No.4, pp.1066-1073 (2006)

( 4 ) D. Nguyen and B. Lehman: "A reconfigurable solar photovoltaic array under shadow conditions", 2008 Twenty-Third Annual IEEE Applied Power Electronics Conference and Exposition, pp.980-986, Austin, USA (2008)

( 5 ) T. Igarashi, T. Kumano, H. Hayashiya, and T. Takino: "Efficiency improvement of rooftop photovoltaic system at railway station", J. International Council on Electrical Engineering, Vol.7, No.1, pp.41-50 (2017)

( 6 ) K. Matsumoto and S. Nomura: "Performance improvement of photovoltaic power generation systems using on-off control methods", Proc. 2014 International Power Electronics Conference (IPEC-Hiroshima 2014 - ECCE ASIA), pp.3218-3224, Hiroshima, Japan (2014)

Masamichi Tanemo (Non-member) received the Master of Engineer-

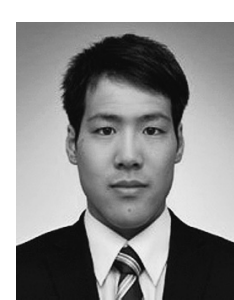
ing degree in electrical engineering from Meiji University in 2018. His research theme in Meiji University was the feasibility study on the circuit configuration change of photovoltaic modules to solve partial shading problems.
Koki Matsudate (Non-member) received the Bachelor of Engineer-

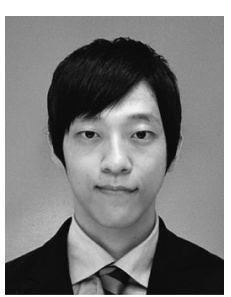
ing degree from Meiji University in 2018. His research theme in Meiji University was the evaluation of the output power properties of photovoltaic modules dependence on partial shading cases.

Shinichi Nomura (Member) received the Doctor of Engineering de-

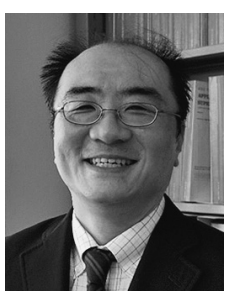
ree in energy science from Tokyo Institute of Technology in 2001. He is now an Associate Professor at the School of Science and Technology, Meiji University. He is a member of IEEJ, IEEE, Cryogenics and Superconductivity Society of Japan, and the Japan Society of Plasma Science and Nuclear Fusion Research. His main research field is the superconducting magnet engineering for power applications, especially energy storage system including the magnet power supply system. 